\title{
Active learning for elementary school based on GeoGebra in SD Swasta Islam Terpadu IQRA'
}

\author{
M Yanti ${ }^{1 *}$, E Rosmaini $^{1}$, E Herawati $^{1}$, R Pane $^{1}$, Sutarman $^{1}$ \\ ${ }^{1}$ Department of Mathematics, Universitas Sumatera Utara, Medan, Indonesia \\ *Email: maulidayanti@usu.ac.id
}

\begin{abstract}
Mathematics is a difficult subject for some elementary school students. One of the reasons is because the teacher still uses traditional methods using textbooks and blackboards so that sometimes it doesn't attract students' interest. Teacher's role in creating a more interactive and interesting learning atmosphere is needed. GeoGebra is an application can be used as an interactive learning medium for Mathematics lessons. This community service will provide training on active learning for Elementary School level using GeoGebra at SD Swasta Islam Terpadu IQRA'. Training about GeoGebra was given to a group of teachers who teach Mathematics. The training included how to install GeoGebra application, how to create basic objects and how to make animations using sliders in GeoGebra. Furthermore, GeoGebra training can also be given to other schools as an alternative to a more interactive mathematics learning media.
\end{abstract}

\section{Keyword: Iterative Learning Media, GeoGebra}

\begin{abstract}
Abstrak
Matematika adalah pelajaran yang sulit untuk dipahami bagi sebagian murid sekolah dasar. Salah satu penyebabnya adalah karena metode pembelajaran Matematika yang masih menggunakan metode traditional yang hanya memanfaatkan buku teks dan papan tulis sehingga kadang tidak menarik minat para murid. Peran guru agar dapat menciptakan suasana belajar yang lebih interaktif dan menarik sangatlah diperlukan. GeoGebra adalah salah satu aplikasi yang dapat dimanfaatkan oleh guru sebagai media pembelajaran interaktif pelajaran Matematika. Pengabdian kepada masyarakat ini akan memberikan pelatihan tentang pembelajaran aktif untuk tingkat Sekolah Dasar menggunakan GeoGebra di SD Swasta Islam Terpadu IQRA'. Pelatihan tentang GeoGebra diberikan pada sekelompok guru yang ikut berperan dalam mengajar Matematika. Pelatihan mencakup instalasi, cara membuat objek dasar dan cara membuat animasi menggunakan slider dengan GeoGebra. Selanjutnya pelatihan GeoGebra ini juga dapat diberikan kepada sekolah lain sebagai salah satu alternatif media pembelajaran Matematika yang lebih interaktif.
\end{abstract}

\section{Kata Kunci: Media Pembelajaran interaktif, GeoGebra}

\section{PENDAHULUAN}

Bagi kebanyakan murid sekolah dasar Matematika adalah pelajaran yang sulit untuk dipahami. Alasannya karena Matematika yang identik dengan rumus dan angka sehingga tidak bisa dihafal melainkan harus dipahami. Alasan lainnya adalah karena metode pembelajaran Matematika yang masih menggunakan metode traditional yang hanya memanfaatkan buku teks dan papan tulis sehingga kadang tidak menarik minat para murid. Untuk menarik minat belajar murid sekolah dasar khususnya dalam belajar Matematika, guru dituntut untuk dapat menciptakan suasana belajar yang lebih interaktif dan menarik.

Salah satu cara mengatasi masalah tersebut adalah dengan memanfaatkan teknologi informasi dalam metode pembelajaran. Guru diharapkan dapat mengemas materi-materi tertentu dengan memanfaatkan perangkat lunak. Misalnya materi tersebut dibuat ilustrasi dalam bentuk animasi bergerak sehingga lebih menarik dan mudah dipahami. Banyak perangkat lunak yang dapat digunakan untuk mengemas materi Matematika menjadi menarik salah satunya GeoGebra. 
GeoGebra adalah software opensource yang salah satu kegunaannya adalah untuk membuat ilustrasi dalam bentuk gambar bergerak atau animasi.

Aplikasi GeoGebra dapat dimanfaatkan untuk membuat ilustrasi interaktif terkait beberapa materi Matematika sekolah dasar seperti penjumlahan, perkalian, sudut, jenis segitiga, bagun datar dan jaring-jaring. Materi-materi ini dapat dibuat animasinya menggunakan GeoGebra. Dengan memanfaatkan perangkat lunak ini diharapkan dapat menjadikan Matematika sebagai subjek yang menarik untuk dipelajari bagi murid-murid sekolah dasar serta dapat meningkatkan daya saing dan kekreatifan guru hingga akhirnya dapat berkontribusi positif bagi mutu pendidikan di Indonesia.

Kemajuan teknologi yang semakin canggih dapat digunakan untuk meningkatkan minat belajar murid sekolah dasar dan meningkatkan mutu pendidikan. Namun, pemanfaatan teknologi informasi di sekolah dasar khususnya di SD Swasta Islam Terpadu IQRA dalam pembelajaran Matematika masih belum optimal sehingga tak heran jika murid tidak terlalu berminat untuk belajar Matematika. Oleh karena itu pada pengabdian ini, tim abdimas USU ingin memperkenalkan salah satu perangkat lunak yaitu GeoGebra pada guru-guru sekolah dasar dengan mengadakan pelatihan terkait cara membuat materi Matematika menjadi gambar gerak menggunakan GeoGebra sehingga dapat meningkatkan minat dan pemahaman murid terhadap pelajaran Matematika.

\section{METODE PELAKSANAAN}

Pengabdian ini telah dilaksanakan pada bulan Oktober dengan memberikan pelatihan bagi guru SD Swasta Islam Terpadu IQRA' dengan harapan guru dapat melaksanakan kegiatan belajar mengajar menggunakan metode pembelajaran interaktif khususnya pelajaran Matematika dengan memanfaatkan perangkat lunak yang sudah ada. Pengabdian dilaksanakan dengan memberi pelatihan GeoGebra kepada guru. Guru diperkenalkan GeoGebra dan cara membuat ilustrasi atau gambar bergerak menggunakan GeoGebra sehingga dapat memudahkan murid untuk memahami konsep Matematika. Untuk keberlanjutan dari pelatihan yang diberikan, mitra akan diberikan perangkat komputer yang telah di-install GeoGebra serta beberapa referensi terkait GeoGebra, sehingga metode pembelajar aktif di kelas dapat dikembangkan oleh para guru.

Metode dan tahapan yang dilakukan pada pelaksanaan pengabdian ini adalah sebagai berikut,

1. Survey Awal, yaitu kunjungan untuk identifikasi permasalah di SD Swasta Islam Terpadu IQRA'. Dalam kegiatan ini, tim abdimas berdiskusi dengan kepala sekolah tentang kendala yang terjadi di SD Swasta Islam Terpadu IQRA'. Kegiatan ini dilakukan pada tanggal 12 Juni 2020. Setelah berdiskusi, kedua pihak, yaitu SD Swasta Islam Terpadu IQRA' dengan tim abdimas setuju melakukan perjanjian kerjasama antar mitra. Kedua pihak setuju untuk mengadakan pelatihan GeoGebra sebagai salah satu cara untuk meningkatkan pembelajaran interaktif khusus bidang Matematika.

2. Menyiapkan bahan pelatihan dan contoh animasi topik Matematika sekolah dasar dengan GeoGebra, yaitu mengumpulkan referensi dan beberapa contoh materi-materi Matematika sekolah dasar yang dapat dibuat ilustrasi menggunakan GeoGebra. Beberapa contoh animasi materi-materi sekolah dasar dibuat ilustrasi menggunakan GeoGebra serta disiapkan juga panduan berupa slide atau referensi terkait dasar GeoGebra dan langkah-langkah membuat contoh animasi di GeoGebra.

3. Mengadakan pelatihan /workshop kepada guru Matematika SD Swasta Islam Terpadu IQRA'. Pelatihan mencakup instalasi, cara membuat objek dasar dan cara membuat animasi menggunakan slider dengan GeoGebra. Saat pelatihan peserta juga diberikan pretest dan posttest untuk melihat peningkatan pengetahuan terkait GeoGebra.

4. Evaluasi, yaitu secara aktif tim abdimas mengecek objek sederhana dan contoh animasi di GeoGebra yang dibuat oleh peserta saat pelatihan berlangsung. Peserta juga diberi kesempatan untuk berdiskusi lewat email jika nantinya mengalami kendala saat menggunakan GeoGebra. 


\section{HASIL DAN PEMBAHASAN}

Sebelum pelatihan dilaksanakan tim abdimas mengumpulkan beberapa referensi untuk disusun sebagai bahan saat pelatihan. Beberapa contoh materi Matematika sekolah dasar yang bisa dibuatkan ilustrasi menarik didapat setelah melihat beberapa video tutorial dari aplikasi Kipin School, membaca buku tematik sekolah dasar dan penelitian tentang GeoGebra serta situs resmi GeoGebra. Beberapa materi sekolah dasar yang bisa dibuat ilustrasi diantaranya adalah sudut, pembagian, perkalian serta penjumlahan dan pengurangan. Langkah-langkah untuk membuat setiap animasi dari materi tersebut, pengetahuan dasar terkait GeoGebra dan penginstalan juga dituliskan secara rinci dalam slide sehingga dapat dijadikan panduan oleh para guru SD Swasta Islam Terpadu IQRA'.

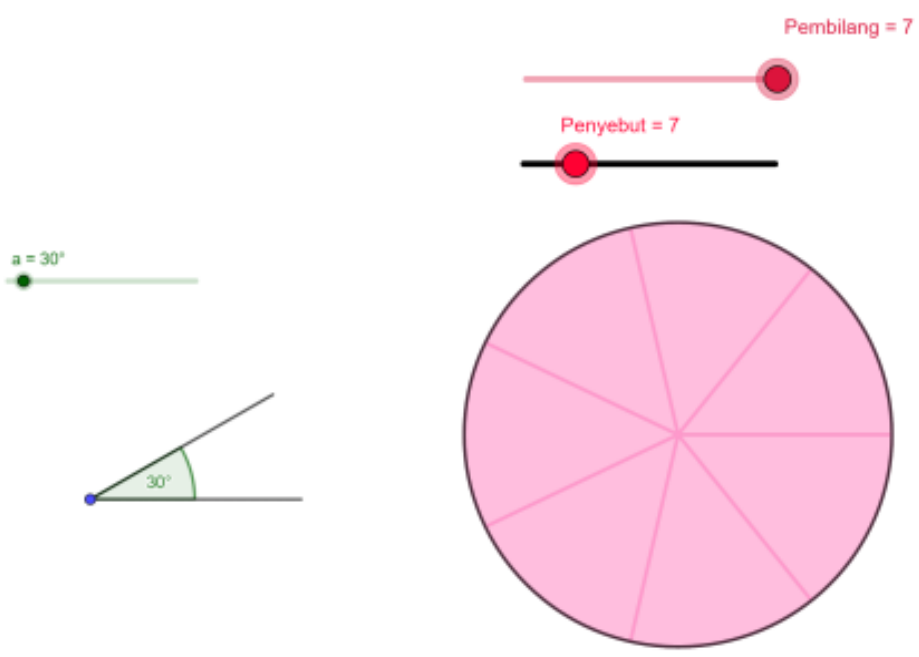

(a) (b)

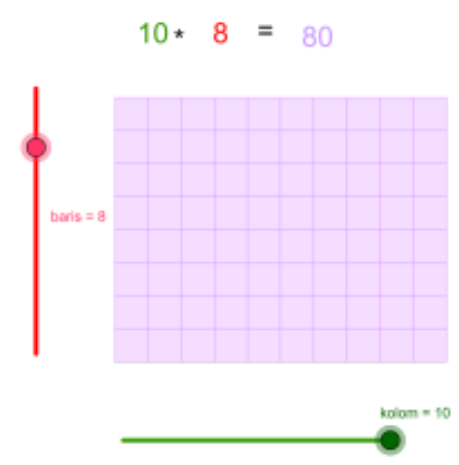

(c)

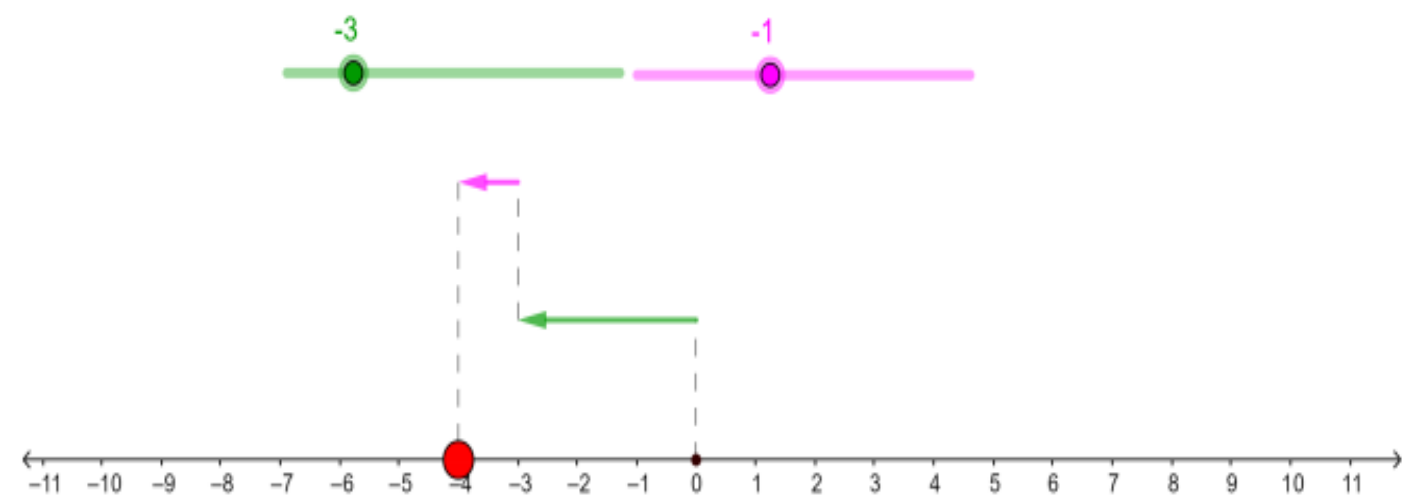

(d)

Gambar 4.1. Beberapa topik Matematika sekolah dasar yang dapat dibuat ilustrasi menggunakan GeoGebra, yaitu (a) sudut, (b) pembagian, (c) perkalian, (d) penjumlahan dan pengurangan.

Beberapa topik Matematika sekolah dasar tersebut kemudian dibuat animasinya menggunakan GeoGebra. Tampilan dari masing-masing topik tersebut pada GeoGebra terlihat seperti pada Gambar 4.1. File ilustrasi dari masing-masing topik yang telah dibuat di GeoGebra ini di simpan di flash disk untuk dibagikan kepada masing-masing peserta. Beberapa referensi lain seperti ebook online yang telat di unduh dari situs GeoGebra beserta instaler dan slide pelatihan 
juga di simpan di flash disk peserta. Para guru bisa membaca kembali saat ingin mengemas dan mengembangkan materi Matematika yang ingin disampaikan dikelas.

Pelatihan GeoGebra dilakukan pada tanggal 12 Oktober 2020 di laboratorium komputer SD Swasta Islam Terpadu IQRA' dan diikuti oleh 13 orang guru. Saat hari pelatihan dilaksanakan, tim abdimas juga dibantu oleh Yulli Hermawati Simatupang, Mahasiswa Statistika angkatan 2018 dan Enita Dewi Br Tarigan, dosen Matematika USU. Keduanya memantau dan membantu peserta saat mengalami kendala saat mempraktekkan GeoGebra saat pelatihan berlangsung. Kepala Sekolah dan perwakilan tim abdimas membuka acara kegiatan ini. Sebelum dan sesudah pelatihan diberikan, peserta diberikan pretest dan posttest untuk mengukur pengetahuan peserta tentang GeoGebra. Berdasarkan pretest dan posttest yang diberikan terlihat ada peningkatan pengetahuan terkait GeoGebra.
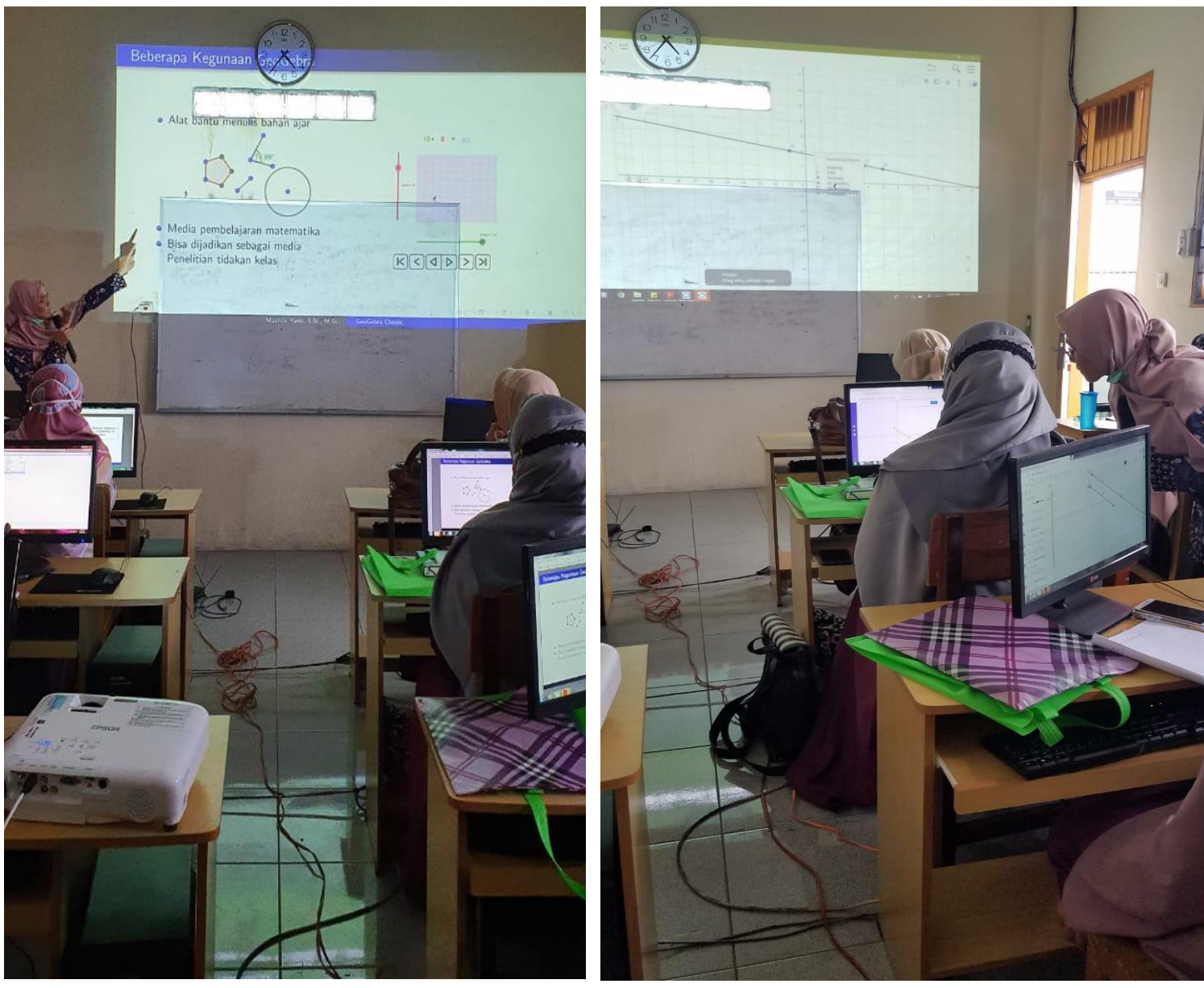

Gambar 3.1. Pelatihan GeoGebra sedang Berlangsung

Pelatihan dimulai dengan instalasi GeoGebra oleh masing-masing peserta pada komputer yang digunakan. Tim abdimas kemudian menjelaskan menu dasar yang ada pada GeoGebra beserta objek sederhana yang bisa dibuat di GeoGebra. Peserta mengikuti pelatihan dengan langsung mempraktekkan cara menggunakan GeoGebra. Setelah peserta dapat membuat objek dasar, pemateri kemudian melanjutkan penjelasan terkait langkah-langkah membuat animasi di GeoGebra menggunakan slider. Langkah per langkah untuk membuat animasi sudut dipraktekkan secara bersama-sama. Peserta juga dijelaskan cara mendapatkan referensi lebih lanjut terkait GeoGebra melalui situs GeoGebra. Kegiatan ini diakhiri dengan pemberian bantuan IT berupa 1 unit laptop yang telah diinstal aplikasi GeoGebra kepada sekolah dan foto bersama. Harapan dari pemberian 
ini adalah agar para guru dapat memanfaatkannya saat mengajar di kelas sebagai salah satu media pembelajaran interaktif.

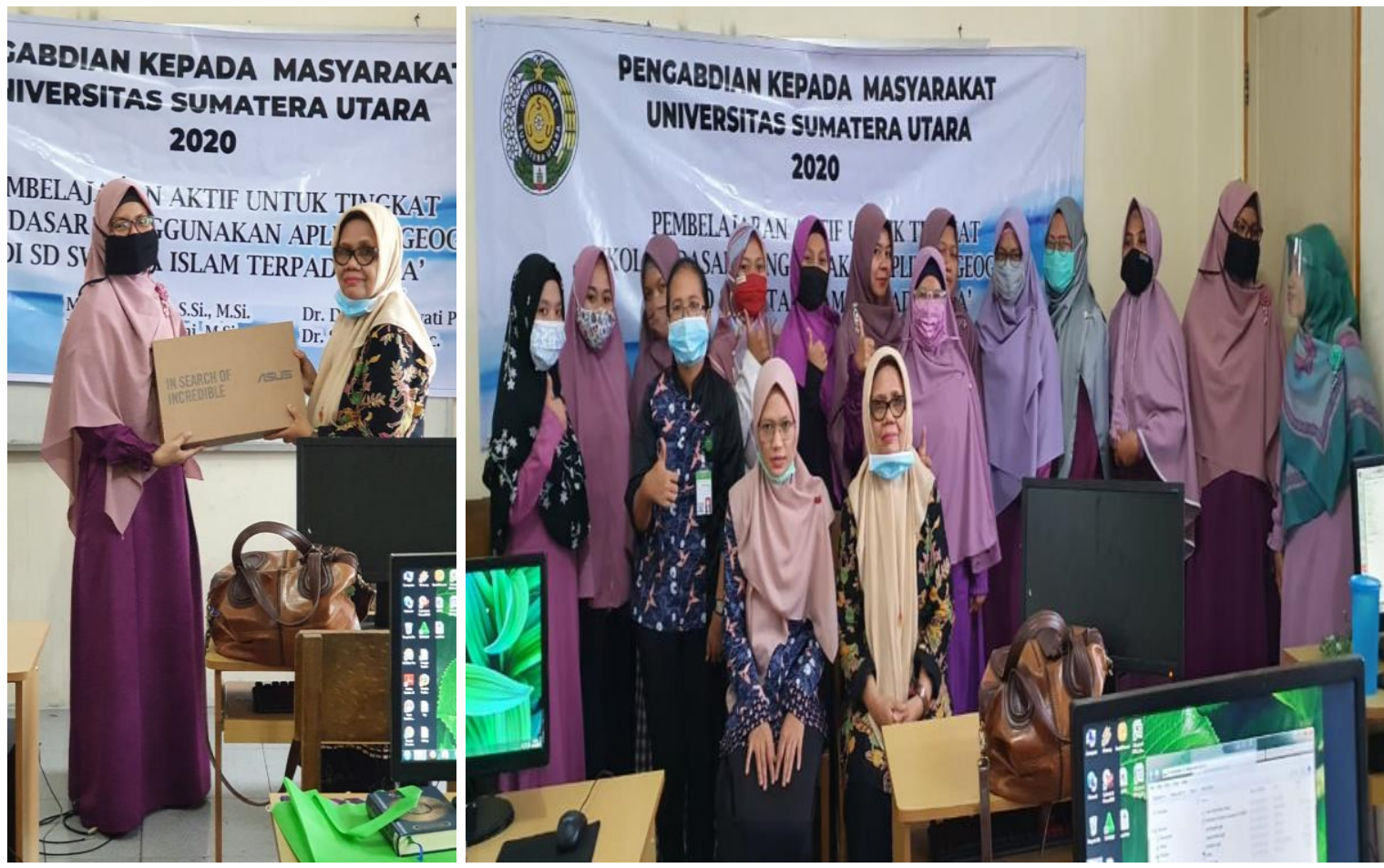

Gambar 3.2 Penyerahan Bantuan IT kepada Sekolah dan Foto Bersama

\section{KESIMPULAN}

Adapun kesimpulan yang diperoleh dari kegiatan pengabdian masyarakat di SD Swasta Islam Terpadu IQRA' yaitu,

1. Kegiatan pengabdian masyarakat yang telah dilakukan mendapatkan respon yang sangat baik dari Kepala sekolah dan para guru.

2. Terjadi peningkatan kemampuan guru khususnya kemampuan dalam menggunakan GeoGebra untuk membuat objek dasar dan slider sehingga dapat digunakan untuk membuat animasi atau gambar bergerak.

3. Guru memiliki Instaler GeoGebra yang dapat di-install pada laptop masing-masing.

4. Guru dapat melihat kembali panduan, referensi GeoGebra dan sarana yang diberikan untuk dimanfaatkan dan dikembangkan sebagai media pembelajaran interaktif di kelas saat mengajar topik Matematika.

\section{UCAPAN TERIMAKASIH}

Artikel ini adalah salah satu luaran hasil pengabdian kepada masyarakat yang dibiayai oleh dana NON PNBP Universitas Sumatera Utara sesuai dengan surat perjanjian penugasan pelaksanaan Pengabdian kepada Masyarakat Program Dosen Wajib Mengabdi Tahun Anggaran 2020. Ucapan terimakasih penulis ucapkan kepada Rektor dan LPPM USU atas bantuan fasilitas dan dana yang disediakan sehingga pengabdian ini terlaksanakan dengan baik. Terimakasih juga kami ucapkan kepada Mitra pada kegiatan pengabdian ini, yaitu SD Swasta Islam terpadu IQRA'. 


\section{DAFTAR PUSTAKA}

Triwahyuningtyas, D., Rahayu, S., and Agustin, W. D. (2019). The impact of geogebra classic application on learning geometry. Journal of Physics: Conference Series, 1381(1), 12-33.

Radović, S., Radojičić, M., Veljković, K., and Marić, M. (2020). Examining the effects of Geogebra applets on mathematics learning using interactive mathematics textbook. Interactive Learning Environments, 28(1), 32-49. 